\title{
¿Práctica real o imaginaria? El sacrificio humano en las sociedades aguada del Periodo de Integración Regional (ca. 600-1200 d. C.) en el Noroeste argentino
}

Pratique réelle ou imaginaire? Le sacrifice humain dans les sociétés Aguada de la Période d'Intégration Régionale (ca. 600-1200 ap. J.C.) dans le Nord-Ouest argentin

Real or imaginary practice? Human sacrifice among Aguada societies during the Regional Integration Period (ca. A.D. 600-1200) from the northwest of Argentine

Ana Solari y Inés Gordillo

\section{(2) OpenEdition}

Journals

Edición electrónica

URL: http://journals.openedition.org/bifea/8478

DOI: $10.4000 /$ bifea.8478

ISSN: 2076-5827

Editor

Institut Français d'Études Andines

Edición impresa

Fecha de publicación: 1 agosto 2017

Paginación: 353-376

ISSN: 0303-7495

\section{Referencia electrónica}

Ana Solari y Inés Gordillo, « ¿Práctica real o imaginaria? El sacrificio humano en las sociedades aguada del Periodo de Integración Regional (ca. 600-1200 d. C.) en el Noroeste argentino », Bulletin de I'Institut français d'études andines [En línea], 46 (2) | 2017, Publicado el 08 agosto 2017, consultado el 06 noviembre 2020. URL : http://journals.openedition.org/bifea/8478; DOI : https://doi.org/10.4000/ bifea.8478

Les contenus du Bulletin de l'Institut français d'études andines sont mis à disposition selon les termes de la licence Creative Commons Attribution - Pas d'Utilisation Commerciale - Pas de Modification 4.0 International. 


\title{
¿Práctica real o imaginaria? El sacrificio humano en las sociedades aguada del Periodo de Integración Regional (ca. 600-1200 d. C.) en el Noroeste argentino
}

\author{
Ana Solari* \\ Inés Gordillo**
}

\begin{abstract}
Resumen
En este trabajo abordamos el tema del sacrificio humano y otros comportamientos posibles vinculados con la muerte en las poblaciones aguada del Noroeste argentino (ca. 600-1200 d. C.). El objetivo es discutir los argumentos que sostienen la existencia de tales prácticas e instar por un adecuado análisis del registro bioarqueológico que debería dar cuenta de ellas. Para ello, luego de sintetizar el estado actual sobre la cuestión, nos interesa confrontar las interpretaciones con las evidencias, explorando particularmente el registro bioarqueológico que ofrece el valle de Ambato (Provincia de Catamarca, Noroeste argentino), referido al sitio La Rinconada y a otros sitios coetáneos de la misma zona. A pesar de tratarse de un registro bioarqueológico cuantitativamente limitado y ambiguo, resulta significativo en la variedad de comportamientos vinculados con la muerte que sugiere, y se constata la dificultad de identificar el sacrificio humano como una práctica social concreta en estas sociedades.
\end{abstract}

Palabras clave: sacrificios humanos, aguada, noroeste argentino, registro bioarqueológico

Posdoctoranda CAPES-PNPD. Departamento de Arqueología, Universidad Federal de Pernambuco. Recife, Brasil. E-mail: anasolari74@gmail.com

** Profesora-Investigadora. Instituto de Arqueología, Facultad de Filosofía y Letras, Universidad de Buenos Aires. CABA, Argentina. E-mail: ibesalu@gmail.com 


\title{
Pratique réelle ou imaginaire ? Le sacrifice humain dans les sociétés Aguada de la Période d'Intégration Régionale (ca. 600-1200 ap. J.C.) dans le Nord-Ouest argentin
}

\author{
Résumé
}

Nous abordons dans ce travail le thème du sacrifice humain et d'autres comportements éventuels liés à la mort dans les populations Aguada du Nord-Ouest argentin (ca. 600-1200 ap. J.C.). L'objectif est de discuter les arguments qui viennent à l'appui de l'existence de telles pratiques et de réaliser une analyse adéquate du registre bioarchéologique qui devrait en rendre compte. Pour cela, après avoir synthétisé l'état actuel sur la question, nous voulons confronter les interprétations avec les preuves, en explorant en particulier le registre bioarchéologique fourni par La Rinconada et par les autres sites contemporains de la vallée d'Ambato (province de Catamarca, Nord-Ouest argentin). Bien que le registre bioarchéologique soit ambigu et limité d'un point de vue quantitatif, il est significatif par la variété des comportements liés à la mort. Cependant, nous constatons la difficulté d'identifier le sacrifice humain comme une pratique sociale concrète dans ces sociétés.

Mots-clés : sacrifices humains, Aguada, Nord-Ouest argentin, registre bioarchéologique

\section{Real or imaginary practice? Human sacrifice among Aguada societies during the Regional Integration Period (ca. A.D. 600-1200) from the northwest of Argentine}

\begin{abstract}
In this paper we address the subject of human sacrifice and other possible behaviors associated with death in the Aguada populations from the northwest of Argentine (ca. A.D. 600-1200). Our aim is to discuss the arguments behind the existence of such practices and encourage an adequate analysis of the bioarchaeological record that would account for them. To achieve this, we will first present a synthesis on the current status of the research topic. In addition, we intend to cross-check the evidence and its multiple interpretations. This will be achieved manily by exploring the bioarcheological record of the Ambato valley (Catamarca province, northwest Argentina), with particular reference to La Rinconada site as well as other contemporary sites from the same zone. Although the archaeological record is ambiguous and quantitatively limited, the variety of the death-related behaviors it displays turns out to be significant, and this confirms the difficulty of identifying human sacrifice as a concrete social practice among these societies.
\end{abstract}

Key words: human sacrifice, Aguada, northwest Argentine, bioarchaeological record

\section{INTRODUCCIÓN}

En la porción meridional del Noroeste argentino (Provincias de Catamarca, La Rioja, San Juan), «Aguada» define y caracteriza al Periodo Medio o de Integración Regional (600-1200 d. C.). En muchas de las investigaciones arqueológicas sobre estas sociedades aguada, se asume casi sin discusión y como una de sus características distintivas, la existencia de prácticas rituales de sacrificios humanos. Esta idea se 
ha sustentado principalmente en las siguientes evidencias: las representaciones iconográficas del «sacrificador» que porta hacha y cabeza cercenada, los hallazgos de hachas de metal, algunas tumbas del cementerio Orilla Norte en el valle de Hualfín (Catamarca), los restos humanos hallados en paredes o pisos de viviendas de varios sitios — considerados como ofrendas de fundación-y otros restos óseos en distintos contextos funerarios o extrafunerarios, junto con la existencia de escenarios arquitectónicos propicios para la ejecución pública de rituales, como las estructuras monticulares de La Rinconada y Choya (Catamarca) o las de La Cuestecilla (La Rioja) (González, 1961-1964; 1983; 1998; González \& Baldini, 1992; Laguens, 2004; Pérez Gollán \& Heredia, 1987; Sempé, 1999; 2003).

Sin lugar a dudas, algunos de estos indicios sugieren la posibilidad de realización de sacrificios humanos en el seno de tales sociedades. No obstante, el registro bioarqueológico — conocido hasta el presente — es muy ambiguo al respecto y no permite hacer afirmaciones tan categóricas sobre este tipo de prácticas vinculadas con la muerte, las cuales son por sí mismas, bastante complejas y difíciles de contrastar arqueológicamente.

Nuestra intención no es negar la posibilidad de que se hayan llevado a cabo sacrificios humanos en estas poblaciones del Noroeste argentino, sino plantear la necesidad de discutir los argumentos que amparen estas afirmaciones e insistir en un adecuado análisis del registro bioarqueológico que permita sustentar o reformular nuestras interpretaciones acerca de los comportamientos mortuorios del pasado. Para ello, tras presentar un panorama sobre el estado actual de la cuestión, nos interesa confrontar las interpretaciones con las evidencias bioarqueológicas, explorando particularmente el registro que ofrece el valle de Ambato (provincia de Catamarca, Noroeste argentino), referido a La Rinconada y a otros sitios coetáneos de la región.

\section{IDENTIFICANDO EL SACRIFICIO HUMANO EN EL REGISTRO ARQUEOLÓGICO}

El sacrificio humano es una práctica mortuoria reconocida mundialmente y llevada a cabo desde tiempos muy antiguos. Es de particular relevancia para la arqueología andina y mesoamericana, donde se han recuperado sólidas evidencias a partir de restos óseos humanos bien preservados en contextos arqueológicos diferenciados, asociados muchas veces a una rica iconografía y a relatos etnohistóricos. Estos datos confirman su existencia en sociedades prehispánicas del continente americano, destacándose los moche o los incas en los Andes, así como los aztecas o los mayas en Mesoamérica (Benson \& Cook eds., 2001; Boone ed., 1984; Bourget, 1998; Dillehay ed., 1995; Duverger, 1979; Graulich, 2005; Sutter \& Cortez, 2005; Tiesler \& Cucina eds., 2007, entre otros).

Sacrificio, del latín Sacrificium, es un acto que comporta múltiples dimensiones (religiosa, ideológica, mítica, cosmogónica, política, económica, etc.) y que, en muchas ocasiones, conlleva una relación de reciprocidad (Caso, 1953), de ofrecer 
para recibir, entre hombres/víctimas y dioses (Hubert \& Mauss, 1929 [1899]). Desde una perspectiva general, la información recogida por la Antropología, la Etnografía, la Etnohistoria y la Arqueología nos muestra el significado, la naturaleza y la función del sacrificio humano como un rito de naturaleza polisémica que puede conceptualizarse como un contrato ritual entre hombres y divinidades por medio de un intermediario que ofrece a un ser sobrenatural algo que debe transformarse de forma súbita o violenta (González Torres, 1985; López Luján, 1993; Verano, 2001; Eeckhout \& Owens, 2008; Oestigaard, 2000). De naturaleza inherentemente destructiva, el sacrificio humano envuelve la trasformación de la ofrenda por medio de esta violencia ritualizada para consagrarla. Asimismo, puede verse como un rito de pasaje que enfatiza la trasformación de un estado al otro (van Gennep, 1972 [1909]; Toyne, 2015).

En términos prácticos puede considerarse que el sacrificio opera cuando el ser u objeto que constituye la ofrenda es destruido. La destrucción caracteriza el sacrificio y la entrega del objeto o del ser constituye la ofrenda (Cazeneuve, 1971); por ello, aunque en determinados ritos ambos aspectos están estrechamente vinculados, el sacrificio siempre implica una ofrenda, pero la ofrenda no implica necesariamente el sacrificio. De allí la dificultad en reconocer indicadores arqueológicos adecuados que no confundan la una con el otro y lleven a interpretaciones apresuradas sobre la práctica de sacrificios humanos en cada «ofrenda» de restos óseos humanos encontrada fuera del ámbito funerario tradicionalmente conocido.

¿Cómo podemos reconocer el sacrificio humano en el registro arqueológico?, sabiendo que es problemático identificarlo con certeza. En principio, los relatos etnohistóricos o fuentes documentales —en particular para sociedades del periodo de contacto colonial_- las manifestaciones iconográficas y la evidencia arqueológica contextual en sí misma, son las principales fuentes de información sobre prácticas que, como los sacrificios humanos, exceden los límites de los comportamientos mortuorios tradicionales (Verano, 1995). En particular, se deberían contemplar una serie de indicadores, entre ellos: la observación de contextos de entierro atípicos o desviados (Geake, 1992), el sentido de posiciones anormales del cuerpo, localizaciones especiales o tratamientos corporales fuera de lo común (Eeckhout \& Owens, 2008), mostrando que los individuos sacrificados son tratados y enterrados de forma diferente a los muertos por causas naturales o accidentales (Toyne, 2015). Al mismo tiempo, otro indicador consistiría en la observación de un tratamiento mortuorio distintivo que refleje la naturaleza especial de la muerte/sacrificio incluyendo evidencia física de la manipulación corporal (Toyne, 2015). Reconocer la intencionalidad de una muerte inducida y los signos de violencia en forma de traumas perimortem son claves al momento de distinguir entre individuos sacrificados $u$ ofrendas secundarias y otros tratamientos posmortem de restos humanos (Verano, 2001). Hay que tener en cuenta que la identificación de muertes no naturales puede incluir lesiones traumáticas en los huesos o únicamente en los tejidos blandos, generalmente invisibles arqueológicamente (Eeckhout \& Owens, 2008). Estas consideraciones son importantes para ayudarnos a interpretar la iconografía del sacrificio humano, 
integrando la narrativa simbólica de las manifestaciones artísticas con la evidencia bioarqueológica, que los restos óseos humanos y su contexto asociado pueden aportar.

\section{AGUADA Y LOS SACRIFICIOS HUMANOS}

El término «aguada» engloba un conjunto de sociedades del Noroeste argentino, entre 600 y 1200 d. C., identificadas a partir de registros regionales y locales que sugieren un incremento de la población — dada la importante densidad de sitios de habitación - con un patrón de instalación más complejo y heterogéneo, así como un perfil novedoso en la explotación o manejo de los recursos agropecuarios (Laguens, 2004; Callegari \& Gonaldi, 2006; Figueroa et al., 2010).

Asimismo, estas sociedades se caracterizarían por la especialización y estandarización de bienes materiales — particularmente en alfarería (Fabra, 2005)_, la incorporación de nuevas técnicas, materiales y modos constructivos, junto con la arquitectura pública y el despliegue de un arte muy elaborado que se expresa en una variedad de materias y lugares (Gordillo, 2007).

El conjunto de estos elementos define un orden sociocultural que, en muchos lugares de la región valliserrana (principalmente en los actuales territorios de Catamarca y La Rioja), bien avanzado el primer milenio de la era, marcan diferencias con los modos de vida precedentes, pero cuya naturaleza es hoy objeto de discusión (Gordillo, 2010). Para algunos autores (Pérez Gollán \& Heredia, 1987; Laguens, 2004) estos cambios forman parte de un proceso de incremento de la complejidad social, con una desigualdad interna marcada por la emergencia de grupos o individuos más ligados al poder político-religioso y al manejo de los recursos económicos.

Con todo, la expresión más ampliamente conocida de Aguada - y tal vez la de más peso a la hora de su reconocimiento — ha sido la potente iconografía centrada en las imágenes felino-antropomorfas y fantásticas. Esta iconografía atraviesa el campo expresivo de diversas poblaciones de la región, dando cuenta así del contacto activo entre las mismas y del uso de este capital simbólico en común al interior de cada una de ellas (Gordillo, 2010).

Parte de estas representaciones visuales — pintadas o grabadas en artefactos y rocas o talladas en piedra o madera- aluden al sacrificio humano, como el personaje del «sacrificador», un motivo que se ha vinculado al ceremonialismo ritual (González, 1961-1964) (fig. 1). Al respecto, uno de los casos más elocuentes es la famosa «teja de Tinogasta» (Lafone Quevedo, 1890), que ha sido interpretada como la representación misma del acto del sacrificio. Se trata de un fragmento de alfarería de tipo Aguada Gris Grabado, donde una figura antropomorfa, con tocado y rasgos felinos, sostiene a un niño con una mano y en la otra tiene un hacha de la que cuelga una cabeza trofeo (González, 1998; Sempé, 1999) (fig. 2). 


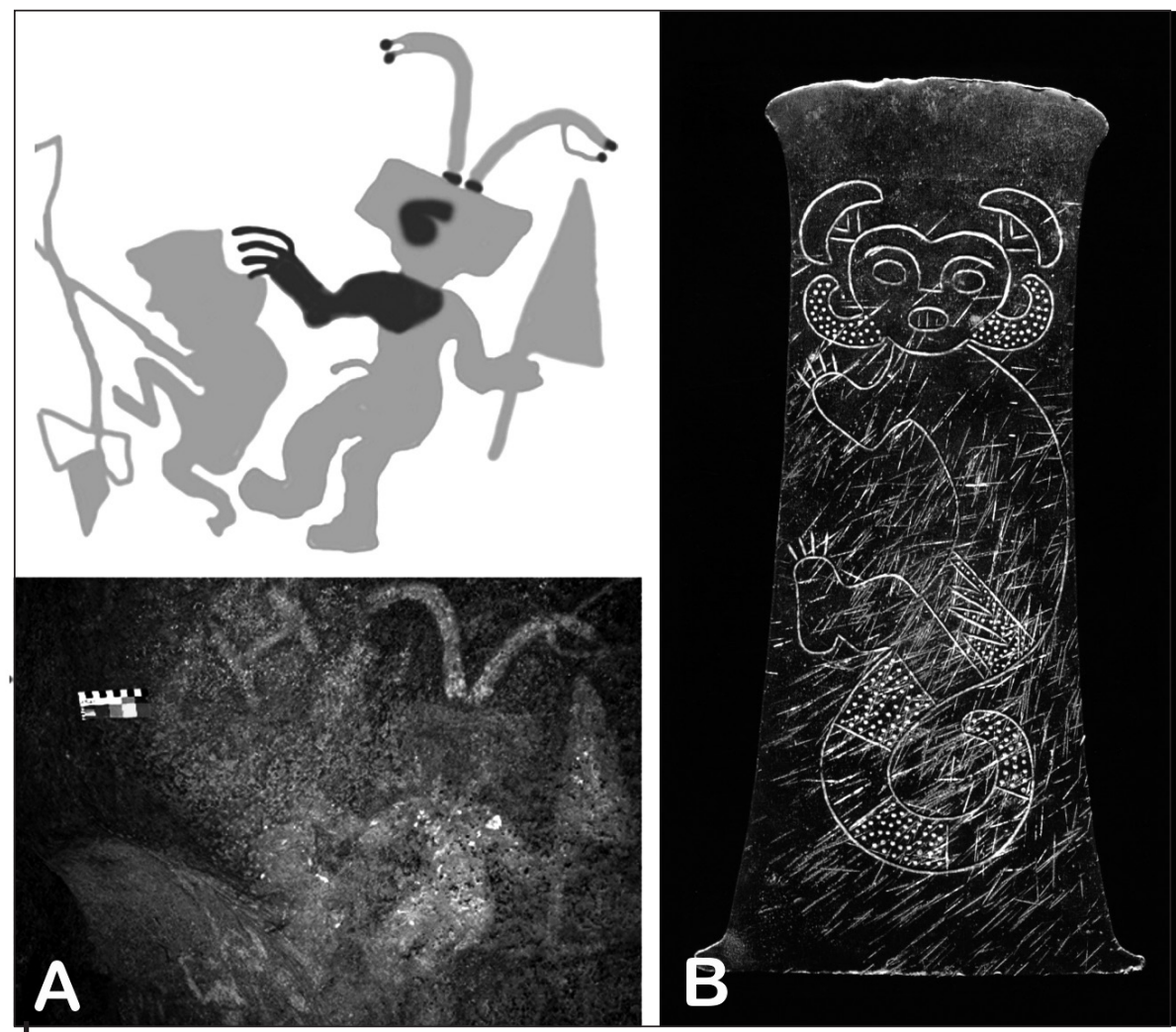

Figura 1 - Iconografía del sacrificio humano en Aguada

A- Escena de arte rupestre de La Tunita, Catamarca

Arriba: calco digital. Abajo: fotografía (Nazar et al., 2013)

B- Hacha de Bronce con figura humano-felínica, Aguada; 37030; largo: $17 \mathrm{~cm}$. Procedencia Santa Cruz, Famatina, La Rioja

Colección Museo Etnográfico «Juan B. Ambrosetti», Facultad de Filosofía y Letras, Universidad de Buenos Aires, Argentina. Foto de Inés Gordillo

Esta imagen iconográfica del sacrificador que porta un hacha y una cabeza cercenada como atributos, ha sido vinculada directamente con la práctica ritual del sacrificio humano como parte de un ceremonial religioso dedicado a una deidad solar que — para algunos autores_ estaría ampliamente extendido en el noroeste argentino y en el área andina en general (González, 1961-1964; 1983; González \& Baldini, 1992).

Al mismo tiempo que la iconografía y los objetos de metal, los hallazgos de restos humanos, en tumbas o fuera de ellas, se destacarían — para algunos autorespor su asociación a los sacrificios humanos. Entre ellas, podemos mencionar las ofrendas de fundación en recintos habitacionales, consistentes en restos humanos 


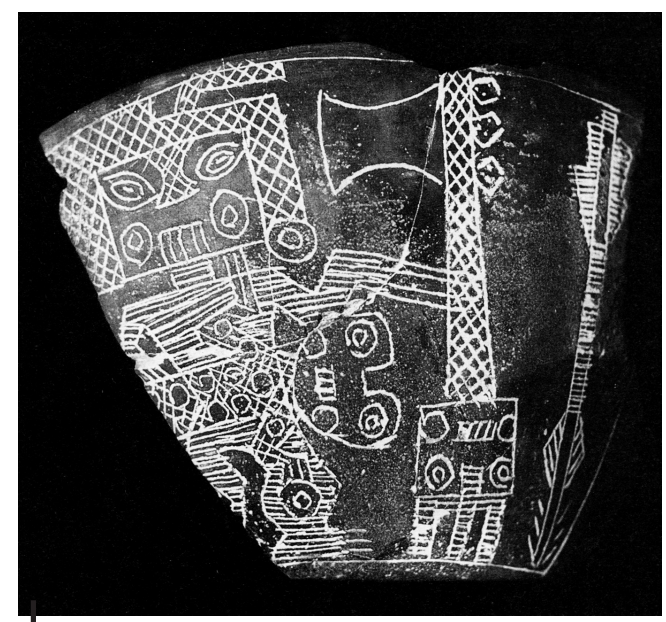

Figura 2 - «Teja de Tinogasta», fragmento de cerámica gris grabado con la imagen del sacrificador y su víctima, procedente de Tinogasta, Catamarca

Colección Museo de La Plata. Foto de Inés Gordillo enterrados dentro de las estructuras constructivas de los sitios Palo Blanco y Barrealito de Azampay (Catamarca) (Sempé, 1999; 2003). Se puede mencionar también el contenido de algunas tumbas aguada del periodo Medio del cementerio «Orilla Norte» en el valle de Hualfín (Catamarca), en particular, la tumba número 108 con un entierro múltiple, la número 128 con un hacha de metal como ajuar funerario (González, 1998) o las tumbas números 45, 81, 83 y 135 con individuos enterrados sin cabeza o con cabezas «cercenadas» (Sempé, 1999; 2003).

Finalmente, los hallazgos de restos óseos humanos asociados a estructuras arquitectónicas monticulares, también han sido considerados como evidencias de ceremoniales de inmolación ritual de seres humanos en dichos espacios destacados (González, 1983; Pérez Gollán \& Heredia, 1987; Pérez Gollán et al.,1996-1997).

$\mathrm{Al}$ respecto, creemos que en muchas de estas interpretaciones ha primado la idea, difundida desde fines del siglo XIX en la arqueología argentina, del sacrificio ritual humano como sinónimo de complejidad social vinculado a una tradición andina. Sin embargo, no se ha evaluado adecuadamente la posibilidad de otras prácticas alternativas que también podrían explicar muchos de estos hallazgos «atípicos», como por ejemplo: los entierros secundarios, el canibalismo, las ofrendas posmortem, la basura ceremonial, los cráneos trofeo, las reliquias, entre otros (Gordillo \& Solari, 2009).

En este sentido, aun cuando el registro bioarqueológico del valle de Ambato en Catamarca —región que abordamos particularmente en este trabajo- es escaso y ambiguo, nos permite reflexionar, junto con otras evidencias asociadas, sobre un abanico de posibles comportamientos mortuorios, entre los cuales el sacrificio constituye una hipótesis más, y no la única.

\section{EL REGISTRO BIOARQUEOLÓGICO DE LA RINCONADA Y OTROS SITIOS DEL VALLE DE AMBATO}

Hasta el momento, no se ha definido el patrón funerario tradicional de las sociedades aguada, un aspecto que parece variar en cada región del Noroeste argentino durante esta época. Solo se conocen cementerios bien definidos para el valle de Hualfín (Orilla Norte, provincia de Catamarca), pero su falta de registro 
en otras zonas puede obedecer a su inexistencia o a su invisibilidad arqueológica. El cementerio Orilla Norte (valle de Hualfín) fue excavado entre los años 1919 y 1930 por V. Weisser, bajo el patrocinio y el financiamiento de B. Muñiz Barreto (Sempé, 1987). Se registraron un total de 216 entierros con 277 individuos, correspondientes a los periodos Temprano, Medio, Tardío e Inca. En particular, un total de 150 tumbas conteniendo 187 individuos entre párvulos, niños, jóvenes y adultos proceden del periodo Medio o de Integración Regional (Sempé et al., 2006). La mayoría de las tumbas correspondía a entierros individuales, depositados en simples fosas de forma cilíndrica u oval, a una profundidad promedio entre 2 y 3 metros, con orientación predominante de norte a sur, en posición genu-pectoral y con ajuar fúnebre variable como piezas de alfarería, metal y piedra (González, 1998). Además de los entierros en cementerios, hay registros de sepulturas vinculadas a los grupos humanos aguada en los espacios habitacionales de sitios como La Cuestecilla (noroeste de La Rioja) o Piedras Blancas (Ambato, Catamarca) (Gonaldi et al., 2007; Gastaldi, 2010).

Dentro de este panorama general, no se han encontrado hasta el momento, en el valle de Ambato, áreas formales de entierro, principalmente por falta de excavaciones arqueológicas en la región. Aun así, exhibe una serie de hallazgos aislados, que serán presentados a continuación. Estos dan cuenta de una variedad de prácticas mortuorias, si bien no permiten definir una conducta regular y generalizada respecto de cómo estos grupos humanos enterraban a sus muertos.

La Rinconada o Iglesia de los Indios es uno de los sitios arqueológicos que se localizan en las planicies bajas del valle de Ambato, al norte del valle de Catamarca, en el sector centro-este de esta provincia. Se integra al sistema de asentamientos del área, dentro del rango temporal (ca. 600-1200 d. C.) y al perfil sociocultural que definen al Periodo Medio o de Integración Regional en la región (fig. 3).

A nivel intersitio son indiscutibles las recurrencias materiales, técnicas y estilísticas que exhibe el registro arqueológico, especialmente en la construcción de los espacios domésticos, así como en los bienes muebles y restos óseos. Los restos humanos que aquí tratamos proceden de las excavaciones realizadas en distintos sitios. Dos de ellos, Iglesia de los Indios y Piedras Blancas, se destacan por la magnitud (alrededor de $15000 \mathrm{~m}^{2}$ y $7000 \mathrm{~m}^{2}$ respectivamente), la complejidad de sus áreas residenciales y, especialmente el primero, por la presencia de arquitectura pública y monumental (Gordillo, 1994; Gastaldi, 2010; Marconetto, 2005). En tanto, Martínez 2 y Martínez 4 son de menor tamaño (unos $700 \mathrm{~m}^{2}$ y $170 \mathrm{~m}^{2}$, respectivamente) y han sido caracterizado como núcleos menores de habitación y/o talleres de producción artesanal (Herrero \& Ávila, 1991; Juez, 1991; Gastaldi, 2010). Asimismo, se mencionan aquí otros hallazgos aislados de restos humanos (LR095 y LR096) en áreas adyacentes a La Rinconada (Cruz, 2006). 

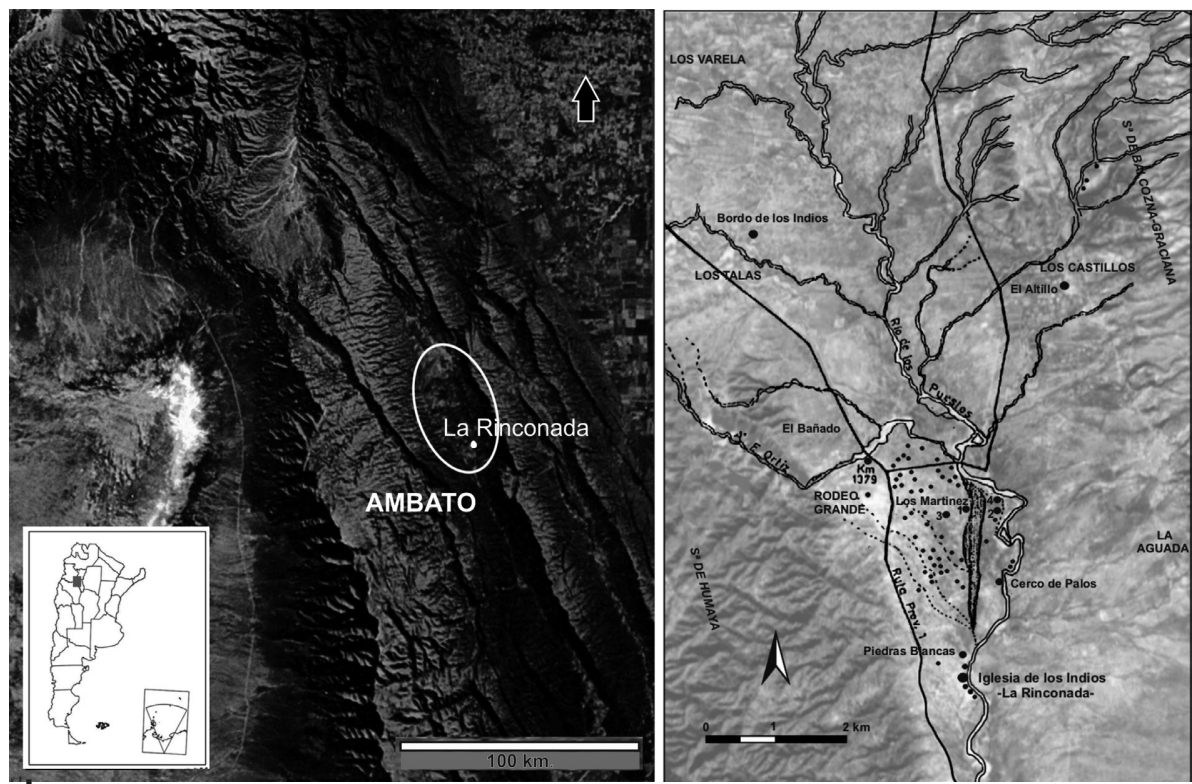

Figura 3 - Ubicación del valle de Ambato en el Noroeste argentino (izquierda) y detalle de la localización de los sitios arqueológicos mencionados en el texto (derecha)

(C) Mapa de Inés Gordillo. A la izquierda, imagen Landsat «Capillitas» (tomada de Gordillo, 2004: 47, figura 3.2); a la derecha foto aérea IGM 2765-304-3 (tomada de Gordillo, 2004: 73, figura 4.1)

\section{1. La Rinconada o Iglesia de los Indios}

Es uno de los sitios más notables del valle de Ambato. Ocupa un área de aproximadamente $130 \mathrm{~m}(\mathrm{~N}-\mathrm{S})$ por $120 \mathrm{~m}$ (E-O) y está formado por un conjunto de estructuras articuladas en una trama ortogonal de unidades adosadas. En planta, el conjunto de las construcciones configura una gran $U$ abierta hacia el poniente (fig. 4).

La forma en que se distribuyen e integran las distintas unidades arquitectónicas en el sitio, permite diferenciar: 1) el espacio público, integrado por la unidad espacial central o plaza y las construcciones que la circundan, incluida la estructura monticular o plataforma que se extiende al sur del sitio; y 2) el espacio residencial, constituido por las áreas de vivienda de los sectores norte y este del emplazamiento.

El primer escenario alude a prácticas eventuales y colectivas de carácter religioso, mientras que el segundo fue parte de la vida cotidiana y corresponde al orden doméstico y privado. En este último se integran varios núcleos de habitaciones en torno a grandes patios, donde se desarrollaron múltiples actividades domésticas vinculadas a la producción de alimentos y bienes, consumo y almacenaje, prácticas rituales, etc., mostrando una estrecha correspondencia con otros sitios coetáneos del mismo valle (Gordillo, 1994). 


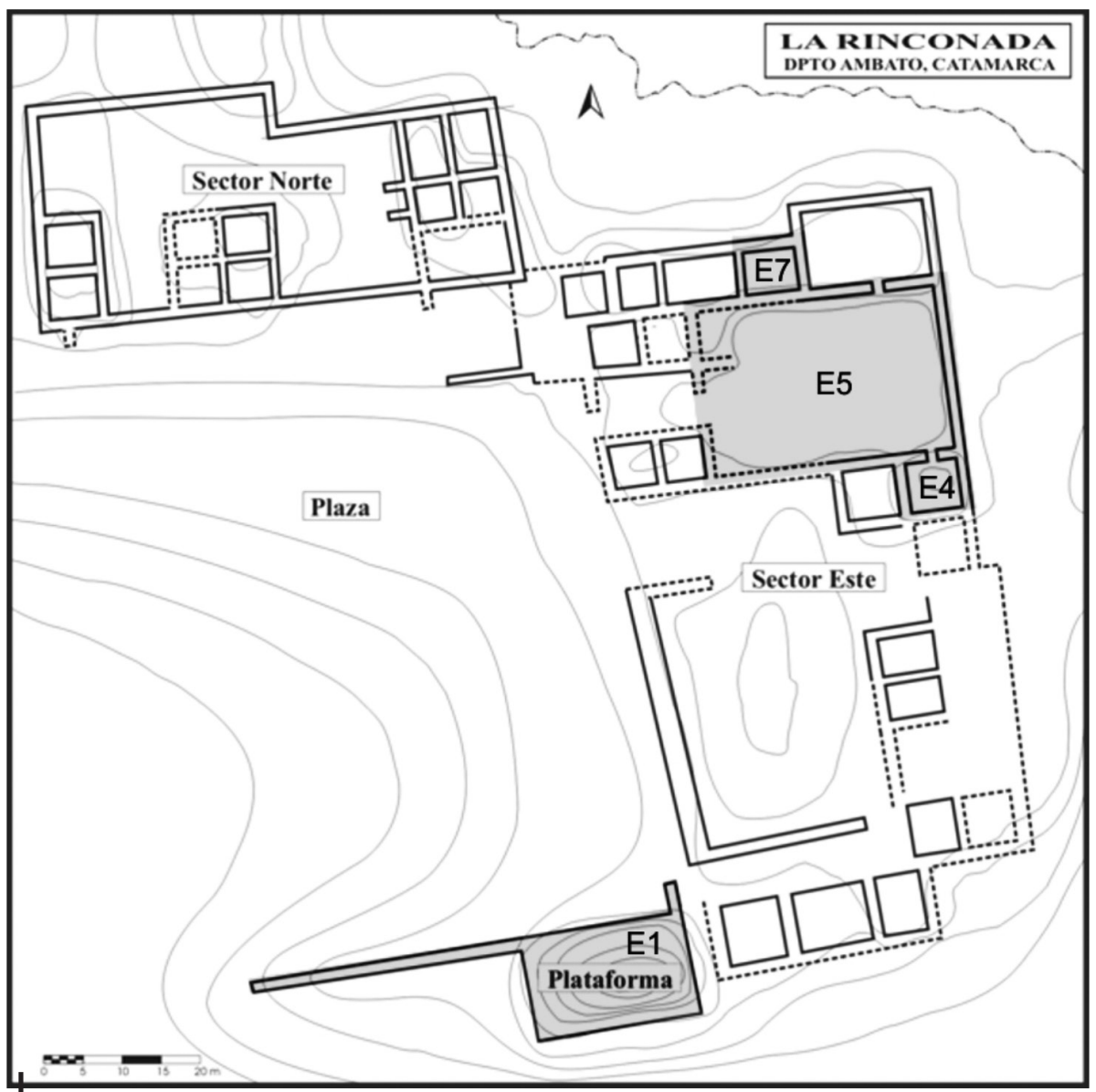

Figura 4 - Planta del sitio arqueológico La Rinconada (Ambato, Catamarca) y estructuras donde se hallaron restos óseos humanos (E1, E4, E5, E7)

Diseño de Inés Gordillo

El estado y la disposición de los abundantes materiales obedece a varios factores. Por un lado, al uso y descarte de los mismos durante la ocupación de las viviendas y, por el otro, a los incendios y al derrumbe de techos y paredes que marcan el abandono del sitio, así como las acciones vinculadas a este último episodio y a los procesos posteriores. En consecuencia, los materiales hallados en los niveles antrópicos de estos recintos corresponden básicamente a desechos de facto y primarios (Schiffer, 1972). Los primeros, distribuidos sobre la superficie de ocupación de cada unidad, no fueron objeto de descarte, pero sí los afectó el colapso arquitectónico y, en algunos casos, la destrucción intencional previa al mismo. Muchos de los elementos hallados sobre la superficie de ocupación, incluyendo los huesos humanos encontrados en algunas estructuras, estaban parcialmente quemados como consecuencia de la acción del fuego durante los incendios de los recintos. Una capa irregular con restos quemados de troncos, 
ramas y paja correspondientes a los techos cubre a estos contextos finales como consecuencia de aquel evento. Como en el resto del área, no hay signos de reocupación permanente posterior a 1200 d. C.

Los restos óseos humanos 1 recuperados en La Rinconada proceden de distintas unidades excavadas, que se describen brevemente a continuación (figs. 5 y 6 ).

La Estructura 1 (E1) es una construcción maciza o un montículo-plataforma (alrededor de 22 por $14 \mathrm{~m}$ de lado y 3,5 m de altura) con un relleno artificial al interior de sus muros. Su interior presenta sedimentos y abundantes desechos o residuos de carácter secundario (tiestos, espículas y trozos de carbón, mazorcas quemadas, huesos, etc.). Entre ellos, los restos óseos humanos son muy escasos: algunos dientes, un fragmento de mandíbula, una falange y un fragmento de
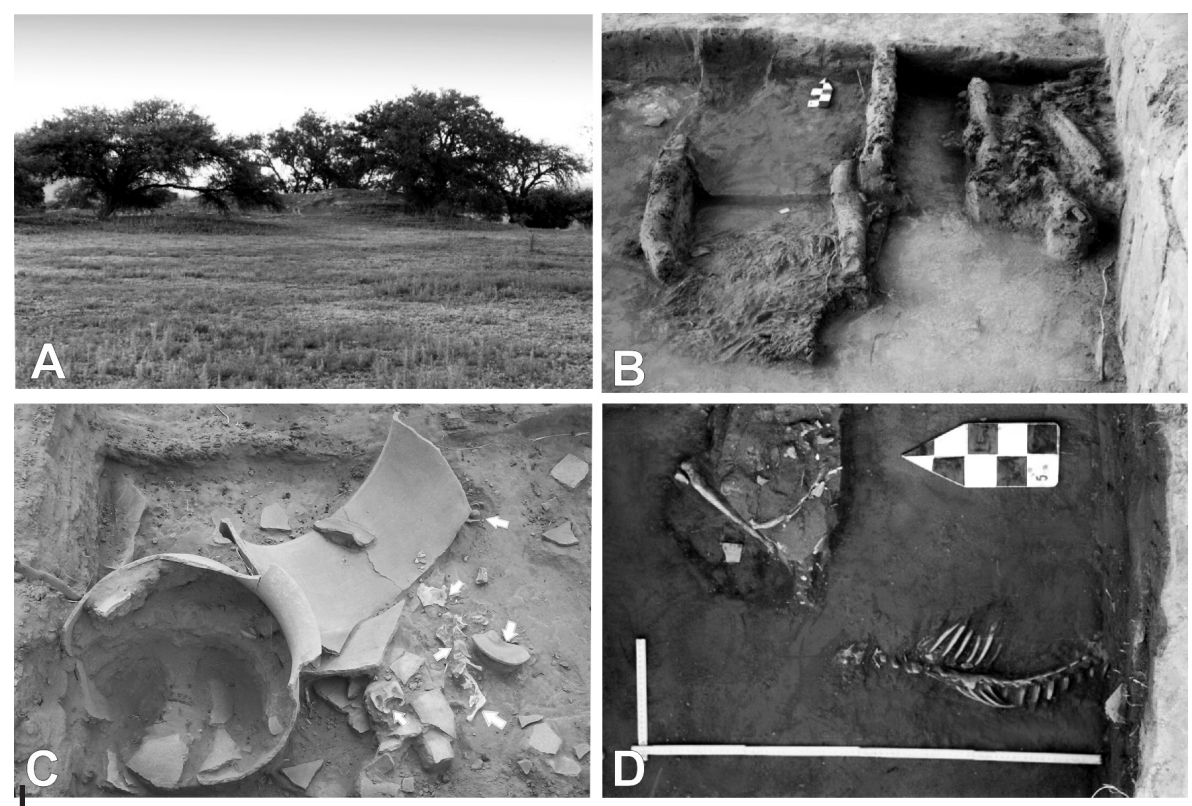

Figura 5 - Estructuras con hallazgos de restos óseos humanos en La Rinconada. A- Vista desde el norte de la estructura maciza, montículo-plataforma (E1). B- Superficie de ocupación de la E4 con los troncos quemados, bajo los cuales aparecieron restos de cerámica y huesos fragmentados. C- Área norte del patio (E5) con materiales diversos sobre la superficie de ocupación (cerámica y huesos fragmentados). D- Debajo de la superficie de ocupación, en el centro de la $\mathrm{E} 7$, donde se enterraron la vicuña y el paquete humano-camélido

(C) Fotos de Inés Gordillo

1 Los métodos osteológicos de observación macroscópica utilizados para la estimación de edad y sexo, así como para la identificación de lesiones traumáticas y otras señales de manipulación intencional en huesos humanos, son los tradicionalmente usados en antropología biológica y bioarqueología (Bass, 1987; Botella et al. 1999; Brothwell 1987; Buikstra \& Ubelaker, 1994; Ferembach et al., 1979; Scheuer \& Black, 2004; Schaefer et al., 2009; Ubelaker, 1978; White \& Folkens, 2000; White \& Folkens, 2005, entre otros). 

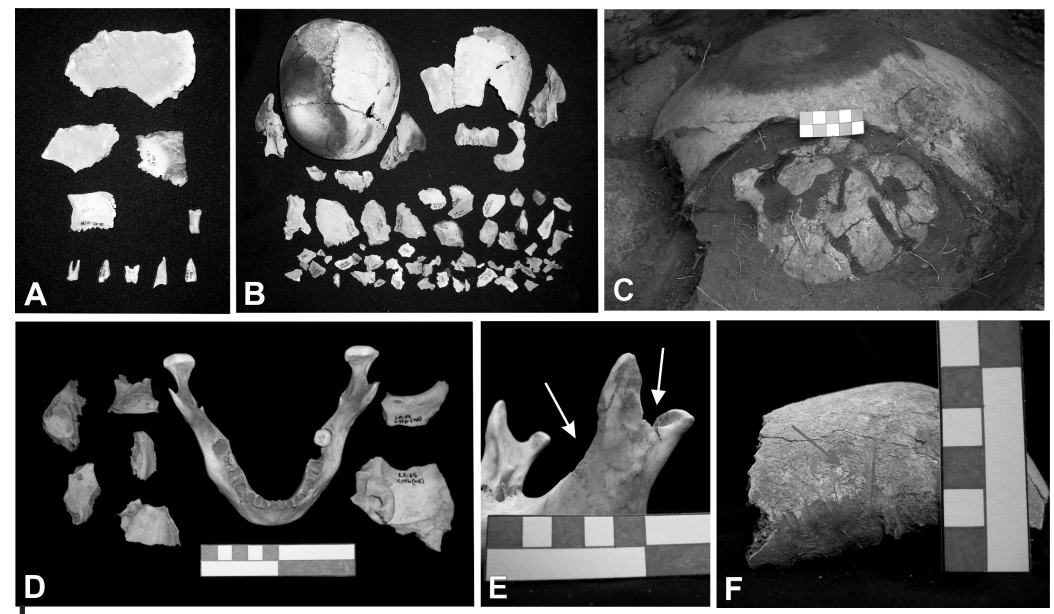

Figura 6 - Restos óseos humanos de La Rinconada

A- Restos humanos del montículo-plataforma (E1)

B- Cráneos humanos (E501 y E502) quemados y fragmentados de la E5

C- Cráneo de subadulto (E503) sin alteraciones, encontrado en el piso de ocupación de la E5

D- Mandíbula con marcas de corte y alteración térmica (exposición indirecta al fuego a baja temperatura) y otros fragmentos de cráneo de la E5

E- Detalle de las marcas de corte en la mandíbula

F- Detalle de fragmento de hueso parietal izquierdo (E502) con marca de corte

(C) Fotos de Ana Solari e Inés Gordillo

cráneo. Corresponden a un número indeterminado de individuos adultos, de edad y sexo desconocidos y no muestran huellas de manipulación humana definidas.

La Estructura 4 (E4) corresponde a una habitación cuyo antiguo piso de ocupación presenta abundantes materiales de distinto tipo (vasijas, artefactos de metal, adornos, huesos de animales, etc.) y un único fragmento de hueso frontal de un individuo adulto de edad y sexo indeterminado, hallado sobre un gran fragmento cerámico de olla. El mismo presenta evidencia de exposición directa al fuego (huesos quemados), pero sin señales claras de manipulación intencional humana. La Estructura 5 (E5) es un gran patio de $550 \mathrm{~m}^{2}$, con galerías o aleros laterales adyacentes a los muros, donde se habrían desarrollado una diversidad de actividades vinculadas al procesamiento de camélidos, la molienda, el almacenamiento de frutos, las prácticas rituales, etc. Numerosos fragmentos de cráneos humanos fueron hallados en un área limitada sobre el piso de ocupación, en el sector norte. Se estimó un número mínimo de individuos (NMI) total equivalente a seis individuos (por número de huesos temporales/apófisis mastoideas), representados casi exclusivamente por cráneos. Sus características son:

- Una mandíbula entera con un molar, asociada a otros fragmentos de cráneo, correspondientes a un individuo de edad adulta, posiblemente de sexo 
femenino. Muestra huellas de cortes perimortem en la rama izquierda que sugieren su desarticulación del resto del cráneo y señales macroscópicas y microscópicas de alteración térmica por exposición indirecta al fuego a baja temperatura (huesos hervidos) (Solari et al., 2015).

- Varios fragmentos de cráneo correspondientes, al menos, a dos individuos diferentes. Uno de ellos, el cráneo E501, es representado por un hueso frontal y ambos huesos parietales completos, ambos huesos temporales y un maxilar superior fragmentados. Presenta características de sexo femenino, de edad adulta, sin marcas de corte, pero con diversos grados de exposición directa al fuego (huesos quemados2). El otro cráneo, E502, es representado por ambos huesos parietales (uno completo y el otro fragmentado), un temporal izquierdo, un malar izquierdo y un maxilar superior fragmentados; parece corresponder a un individuo masculino de edad adulta. Presenta también diversos grados de exposición directa al fuego y una marca de corte intencional perimortem en el hueso parietal izquierdo, probablemente como resultado de un golpe con un objeto corto-contundente de filo metálico (Hugo Yacobaccio, comunicación personal 2008).

- Un pequeño cráneo sin mandíbula (cráneo E503) hallado cubierto por una vasija invertida. Corresponde a un individuo subadulto de edad estimada entre 6 y 8 años, de sexo indeterminado y con señales de hiperostosis en el occipital (Inés Baffi, comunicación personal 2008). No presenta señales de exposición al calor, ni lesiones traumáticas de ningún tipo.

- En el pasillo de comunicación con el recinto ubicado al norte se encontraron numerosos fragmentos de cráneos con diferentes grados de exposición directa al fuego. Su estado de conservación permitió identificar algunos huesos diagnósticos, tales como, porciones de huesos temporales (apófisis mastoideas) y maxilares superiores, así como otros huesos muy fragmentados no identificados. Corresponden al menos a tres individuos distintos de edad adulta y sexo indeterminado.

La Estructura 7 (E7) es una habitación ubicada en la rama norte del sitio. Si bien se hallaron huesos humanos en distintos depósitos inferiores al piso de ocupación, la mayoría estaba sobre el mismo. El NMI es de dos individuos adultos jóvenes de sexo indeterminado, con buen estado de conservación a pesar de su alta fragmentación y signos de impacto y de exposición al calor en pocos fragmentos. Sus características son:

- Maxilar superior derecho procedente del área central del recinto, con seis dientes, malar casi completo, una porción del hueso temporal y esfenoides, incluyendo el ángulo inferior derecho de la cavidad orbitaria. Fragmento de maxilar superior izquierdo, hallado en el sector centro-norte del recinto, con

2 Debido a los incendios que marcaron el fin de la ocupación en La Rinconada, resulta difícil interpretar el carácter intencional antrópico de la quema parcial de los huesos encontrados en esta y otras estructuras del sitio, situación que esperamos pueda ser clarificada a partir de futuras excavaciones y nuevos análisis sobre los restos óseos. 
ocho dientes parcialmente rotos y fragmentos de maxilar inferior derecho con cinco dientes, que corresponderían al mismo individuo.

- Pequeños fragmentos de cráneo quemado y restos de un occipital fracturado, hallados en el sector SE del recinto.

- Por otra parte, también se hallaron en un contexto diferencial, cuyo significado se discute posteriormente, restos bien preservados de huesos humanos junto con huesos de camélidos domésticos y silvestres enterrados en el área central de la vivienda. De cada taxón se reconocieron los siguientes huesos: un húmero, un radio y un fragmento de mandíbula con dientes de Homo sapiens; falanges, metatarso, metacarpo, radio y hueso largo de Vicugna vicugna; radio, metapodio, costillas y hueso largo de Lama glama.

En síntesis, los restos óseos humanos de La Rinconada se pueden agrupar de acuerdo con los tres contextos de hallazgo registrados hasta el momento, cada uno de los cuales presenta una problemática y un significado diferencial:

A. Cráneos dispersos sobre los pisos de ocupación (E4, E5 y E7). Se contabilizó un NMI de nueve individuos adultos y subadultos de ambos sexos, altamente fragmentados, con diversos grados de exposición al fuego (directo e indirecto) y algunas huellas de corte intencional perimortem (desarticulación y golpes con objeto corto-contundente de metal). Hay que señalar una posible selección intencional de partes del esqueleto, con ingreso y conservación de cráneos humanos dentro de un espacio de uso doméstico (¿canibalismo?, ¿reliquias?, ¿cráneos trofeo?).

B. Huesos enterrados en un pozo bajo el área central del antiguo piso de la habitación (E7) junto a restos óseos de camélidos (¿ofrendas?, ientierros secundarios?).

C. Huesos dentro del montículo-plataforma (E1), como parte de los desechos secundarios que conforman el relleno artificial de la estructura (ibasura ceremonial?).

\section{2. Piedras Blancas 3}

El sitio se ubica a unos 300 m de distancia en dirección NO de La Rinconada. La proximidad y la contemporaneidad de ambos sitios permiten considerarlos como parte del mismo complejo de instalación, aun cuando no se define una continuidad espacial - constructiva o material- entre los mismos (Gordillo, 2007). Piedras Blancas ocupa un área aproximada de $100 \mathrm{~m}$ (E-O) por $70 \mathrm{~m}$ (N-S) y fue dividido en tres sectores con fines descriptivos: Sector I, II y de Transición.

El Sector de Transición se ubica al centro del sitio y es desde donde se accede al mismo. Se trata de un área libre de construcciones cuya superficie se encuentra

Los sitios Piedras Blancas y Los Martínez fueron excavados por otros equipos de arqueólogos; por lo tanto, los datos presentados en esta breve descripción de los hallazgos de restos óseos humanos corresponden a las publicaciones disponibles consultadas. 
deprimida respecto a los otros dos sectores. El Sector I se ubica hacia el oeste del sitio y está compuesto por una elevación monticular con una superficie aproximada de $50 \mathrm{~m}$ por $40 \mathrm{~m}$, orientada en dirección NO-SE. El Sector II se ubica hacia el este del sitio, posee un muro de piedras de cuarzo blanco de $39 \mathrm{~m}$ de largo orientado en sentido N-S que presenta en su parte central una interrupción o abertura de 7 m que permite el acceso desde el Sector de Transición al Sector II. Dentro de este sector se ubican 7 recintos y 3 espacios abiertos o patios.

Se hallaron restos óseos humanos en el Sector I (montículo) y en el Sector II (Recinto H) (Marconetto, 2005).

El sector I consiste en una estructura monticular de planta oval de 64 m por $56 \mathrm{~m}$. Entre muchos otros materiales del relleno, se hallaron escasos restos de cráneos humanos.

En el Recinto $\mathrm{H}$, ubicado en el sector norte del sitio, se recuperaron 3 entierros de individuos infantiles, de distintas edades, con y sin ajuar funerario asociado. Son caracterizados por Cruz (2004) y Marconetto (2005) de la siguiente manera:

- Sepultura 1: fosa simple de forma oval bajo el piso de ocupación, cercana al muro sur. Es el entierro primario de un infante (0 a 1 año) en posición decúbito lateral izquierdo. Los restos óseos, en regular estado de conservación, muestran conexión anatómica.

- Sepultura 2: ubicada bajo el piso de ocupación y parcialmente bajo el muro este del recinto, en una fosa de forma irregular conteniendo los restos óseos de un infante (1 a 2 años) en buenas condiciones de conservación, enterrado en posición flexionada decúbito lateral derecho, en conexión anatómica. Contiene ajuar asociado: cuatro garras de felino, un aro de bronce, una estatuilla de camélido de cerámica y dos artefactos óseos.

- Sepultura 3: situada bajo el piso de ocupación perpendicular al muro sur del recinto. Es el entierro directo y primario en fosa simple de forma oval de un infante (2 a 4 años), depositado en posición dorsal extendida. Los restos óseos exhumados muestran conexión anatómica, mal estado de conservación y están parcialmente asentados sobre una laja irregular cubierta parcialmente por una capa de cobre rojo. El material asociado incluye vasos de alfarería (uno con restos de pigmentos), una mano de molino, cuentas de turquesa, un perforador en cuarzo roto y parte de una estatuilla antropomorfa de cerámica.

\section{3. Los Martínez}

Unos kilómetros más al norte, en el mismo valle, existe una concentración de sitios, entre los cuales destacan Los Martínez 1, 2, 3 y 4 (Pérez Gollán \& Heredia, 1987). En algunos se recuperaron restos óseos humanos (Juez, 1991; Herrero \& Ávila, 1991) cuyos datos sintetizados se exponen a continuación.

El sitio Martínez 2 está formado por dos sectores de recintos habitacionales separados por un patio central y galerías adosadas. En dos recintos del sector Oeste se recuperaron 
numerosos fragmentos óseos humanos sobre el piso de ocupación, asociados a piezas cerámicas y huesos de camélidos. Los huesos humanos corresponden en su mayoría al esqueleto poscraneal, aunque también se hallaron restos de cráneos, perteneciendo a individuos de distintas edades (adultos y subadultos) y presentando en muchos casos huellas de manipulación intencional. Según Juez (1991) se contabilizaron siete individuos identificados por los huesos poscraneales. También, señala que los cráneos debieron haber sido sometidos a un tratamiento intencional diferente del resto del esqueleto, puesto que solamente estos se hallaron quemados; además estaban multi-fragmentados y posiblemente sometidos al fuego aún con sus partes blandas (comunicación personal de Martín Laguens, en Juez, 1991: 92). Junto a las habitaciones, en una galería, también se registraron fragmentos de huesos humanos en asociación a otros materiales (cerámica, hueso, lítico, etc.). En el sector Este, separado del anterior por un patio, solo se halló una mandíbula humana asociada a dos vasijas cerámicas en el área de galería.

En otro análisis de este mismo material, realizado por Cruz (2004), el autor también estimó un NMI de siete individuos, la mayoría con indicadores sexuales femeninos. El 38\% de los restos óseos presentaban modificaciones antrópicas intencionales: quemado de huesos largos, fracturas intencionales (principalmente sobre las costillas frescas), huellas de pintura encontradas sobre fragmentos de huesos parietales, y presencia de marcas de corte. Según Cruz (2004), estas alteraciones habrían sido el resultado de actividades de desmembramiento, descarnamiento, golpes, decoración y quemado.

En Martínez 4 se excavó parte de los sectores de habitación y de galería. Allí se recuperaron diversos tipos de materiales, abundantes fragmentos cerámicos, objetos de metal, piedra y hueso y numerosos fragmentos de huesos humanos hallados sobre el piso, asociados a piezas cerámicas (Herrero \& Ávila, 1991). El examen detallado de este material, realizado por Baffi \& Torres (1995-1996), dio como resultado un NMI de siete individuos (a partir del aparato bucal), con tres subadultos y cuatro adultos. Entre estos últimos, dos eran de sexo masculino, uno femenino y el otro indeterminado. Las autoras señalan el buen estado de conservación general de los huesos, aunque se hallaron muy fragmentados y en ciertos casos quemados. Aparecen sobre el piso de ocupación o en el material de relleno y destacan la ausencia de tejido óseo esponjoso en varios huesos largos y posibles marcas intencionales y de utilización que requerirían de estudios más exhaustivos.

\section{4. Otros sitios}

Finalmente, Cruz (2006) también menciona otros dos sitios con restos óseos humanos próximos a Piedras Blancas y a La Rinconada, de los cuales no encontramos más información publicada que la que sigue a continuación. Según el autor, el primero, LR095, correspondería a una estructura de tipo fosa simple, conteniendo el entierro primario de un individuo adulto hallado aparentemente en posición extendida y dorsal. En cuanto al segundo, LR096, consistiría en 
una sepultura múltiple de tipo fosa simple de $3 \mathrm{~m}$ de diámetro por 0,50 m de profundidad. Contiene restos óseos humanos dispersos y mezclados entre sí sobre toda la superficie de la fosa, en muy mal estado de conservación, asociados a restos óseos de camélidos en conexión anatómica estricta y para la cual estimó un NMI aproximado de entre 8 a 25 individuos adultos.

\section{DISCUSIÓN Y CONSIDERACIONES FINALES}

A pesar de las múltiples evidencias sobre la práctica de sacrificios humanos existentes en los sitios andinos y mesoamericanos, un caso en particular — con un registro bioarqueológico similar al del valle de Ambato y equivalentes dificultades interpretativas-, nos sirve para ilustrar cómo el hallazgo de contextos inusuales o fuera de lo común puede llevar a los investigadores a pensar en otras prácticas mortuorias distintas al sacrificio. Se trata de los restos óseos humanos de los sitios de las fases Las Pircas (CA-09-27, CA-09-28, CA-0952) y Tierra Blanca (CA-09-71, CA-09-73, CA-09-77) en el alto valle de Zaña, Perú. En estos, se hallaron huesos humanos fragmentados y dispersos, algunos asociados con fauna o presentando marcas de corte y señales de quemado, que permitieron sugerir la alternativa de canibalismo (Verano \& Rossen, 2011).

En este sentido, pruebas de muy variado tenor nos invitan a reflexionar acerca de la práctica de sacrificios humanos en las sociedades aguada del Noroeste argentino. Desde la sugestiva iconografía del «sacrificador» y los objetos de carácter ritual como las hachas de metal, hasta los hallazgos de restos óseos en contextos funerarios y extrafunerarios, ¿serían todos ellos indicadores arqueológicos de la práctica ritual de sacrificios humanos? y ¿qué nos revela en particular el registro bioarqueológico? Tomando el conjunto de los restos óseos de los sitios mencionados del valle de Ambato y comparándolos, encontramos básicamente dos contextos:

A. Contextos funerarios:

- Entierros primarios, individuales, de adultos y subadultos, posiblemente de ambos sexos, con o sin ajuar funerario asociado (Piedras Blancas y LR095).

- Entierros secundarios de tipo mixto, humano-camélido (La Rinconada y LR096).

B. Contextos extrafunerarios:

- Huesos humanos dispersos sobre los pisos de ocupación al interior de unidades residenciales (La Rinconada, Martínez 2 y 4).

- Huesos humanos dentro del relleno de estructuras monticulares o plataformas (La Rinconada, Piedras Blancas).

Estos contextos y estas características de los conjuntos óseos pueden aludir a una diversidad de comportamientos mortuorios que incluyen, además de prácticas funerarias más tradicionales como entierros primarios o secundarios, otras prácticas vinculadas con la muerte, atípicas para los contextos extrafunerarios. Como 
mencionamos anteriormente, en lo que concierne al registro bioarqueológico del valle de Ambato, los restos óseos humanos son cuantitativamente limitados, pero significativos en cuanto a la variedad de comportamientos y prácticas que sugieren: entierros secundarios, canibalismo, ofrendas, basura ceremonial, cráneos trofeo, entre otros (Gordillo \& Solari, 2009).

Al respecto, vimos cómo varios elementos pueden prefigurar la idea del sacrificio humano en el valle de Ambato. Nos referimos, por un lado, a la iconografía de estilo Negro Grabado típica de la región, y por otro, a un registro bioarqueológico que incluye cabezas aisladas y «cercenadas», huesos humanos fragmentados dentro de estructuras monticulares, dispersos sobre los pisos de ocupación de unidades residenciales, o enterrados debajo de ellas. Sin embargo, del análisis de la evidencia bioarqueológica reunida hasta el momento, no se desprende necesariamente que dichos conjuntos de restos óseos humanos sean producto de este tipo de práctica, especialmente teniendo en cuenta que la misma no debe confundirse con la ofrenda secundaria de restos humanos (Verano, 2001).

Las marcas de corte, fracturas u otras señales de trauma que presentan algunos huesos, pueden llevarnos a pensar tanto en la posible causa de muerte, como en registrar tratamientos perimortem o posmortem de los cuerpos que pudieron llevarse a cabo con distintos propósitos y en diferentes momentos. En este sentido, los huesos humanos hallados sobre los pisos de ocupación o los que fueron enterrados en los sitios del valle de Ambato, no presentan per se ningún indicador definitivo de la práctica del sacrificio (Gordillo \& Solari, 2009). Lo mismo ocurre con los huesos humanos asociados a los montículo-plataformas de La Rinconada y Piedras Blancas.

En relación a estos montículos, los muy escasos huesos humanos hallados en el relleno interior de las estructuras monticulares, igual que el resto de los materiales asociados, son desechos o residuos de carácter secundario. Por lo tanto, no son indicadores directos de la mutilación e inmolación de individuos en prácticas de sacrificios humanos, como ha llegado a ser sugerido en algunas ocasiones (González, 1983). Esto ya fue señalado hace varios años por una de nosotras (Gordillo, 1994) en un estudio general sobre La Rinconada que, entre otras cosas, postula el carácter ceremonial del sitio en razón de su tratamiento arquitectónico, aspecto que fue profundizado en trabajos posteriores (Gordillo, 2004; 2007).

En esta ocasión, los rasgos y las características constructivas particulares de la plataforma principal (E1) de La Rinconada fueron analizados, definiéndose también su proceso de formación en distintos episodios constructivos a lo largo de varios siglos. Si bien se abordó la función ritual de esta unidad, no fue considerada como un espacio escenográfico montado para el sacrificio. Los restos óseos allí recuperados - entre los cuales los huesos humanos son decididamente escasos-, no pueden interpretarse como producto directo de actividades llevadas a cabo en su superficie, dado que formaban parte del relleno constructivo que se usó para darle condición maciza a la estructura. En este sentido, considerando que las características de estos materiales de relleno permiten encuadrarlos como desechos o basura de origen doméstico — producto de actividades de descarte, 
limpieza y traslado - es probable que los contextos primarios de procedencia hayan sido, como en los otros casos analizados, las habitaciones y los patios del área residencial. Lo mismo puede pensarse para el montículo-basurero del sitio Piedras Blancas.

Cabe reiterar que el sacrificio humano es un tema complejo y difícil de constatar arqueológicamente cuando los datos empíricos son imprecisos, como creemos es el caso del valle de Ambato en particular y de Aguada en general. La identificación del sacrificio humano resulta ser un asunto bastante polémico, dado que nociones preconcebidas pueden llevar a interpretaciones sesgadas del registro arqueológico (Verano, 2001). Consideramos que esto último pudo haber sucedido con Aguada, a partir de una caracterización decimonónica como sociedad compleja con influencias andinas. Pudo pasar también a partir de la confusión sacrificio-ofrenda, donde casi cualquier hallazgo de restos humanos fuera de lo «normal» ha sido mayormente vinculado a la idea de los sacrificios, sin tener en consideración la variabilidad de comportamientos mortuorios que estas sociedades pudieron llevar a cabo, y con ello, imaginar otras alternativas distintas al sacrificio.

Es importante resaltar que esta última reflexión no contradice la propuesta inicial de no descartar el sacrificio como práctica ritual posible. Tampoco podemos ignorar que la iconografía Aguada muestra que la idea del sacrificio humano estuvo presente en el imaginario colectivo de aquellas poblaciones del Noroeste argentino, al menos en las dimensiones míticas o cosmogónicas, por más que — hasta el momento — la evidencia arqueológica y bioantropológica no nos permita definirlo a ciencia cierta y como práctica social concreta.

Con limitada frecuencia, el arte mueble y rupestre de estas sociedades exhibe representaciones del acto sacrificial humano, mencionadas e ilustradas al principio. Se trata de algunas imágenes grabadas sobre cerámicas o talladas en objetos de piedra y de pictografías localizadas, principalmente, en el sector sur de la Sierra de Ancasti (Catamarca). Sin embargo, creemos que las imágenes representadas no tienen necesariamente un valor estrictamente referencial. Nuestro acercamiento perceptivo, con la imagen como un fenómeno representacional y la identificación de ciertas imágenes con elementos o experiencias del mundo real, no implica que estas imágenes sean representaciones de los mismos en un sentido referencial (Malafouris, 2007).

Así, siguiendo estas ideas, el modelo representado puede extraerse del mundo físico natural/cultural, de prácticas sociales concretas o bien del imaginario mítico. Una imagen puede aludir a seres, relatos o escenas de carácter mitológico, sin que refiera a prácticas sociales cotidianas o eventuales ${ }^{4}$. Desde esta perspectiva, la representación del sacrificio humano puede referir tanto a una práctica social

4 Para ilustrar esta idea podemos tomar como ejemplo el conocido cuadro «Saturno devorando a un hijo» (1820-1823) de Francisco de Goya —también su antecedente pintado por Peter Paul Rubens en 1636 - donde el dios Saturno de la mitología romana, o Crono de la griega, es representado en el acto de comer a uno de sus hijos. Se trata de una escena de carácter claramente mitológico que lejos está de aludir a la práctica concreta del canibalismo filiar en las sociedades occidentales, sea en Grecia, Roma o Europa de los siglos XVII o XIX. 
concreta como a las que se relacionan con el mito o el imaginario colectivo. En este último caso, el sacrificio puede tener existencia solo en la esfera mítica que se expresa y se representa a través del arte; como tal, es otro factor de ambigüedad que incide y cuestiona las evidencias e interpretaciones de la existencia o inexistencia del sacrificio humano en algunos contextos sociales del pasado.

Por último, creemos que la necesidad de contar con indicadores bioarqueológicos para la identificación del sacrificio humano, unida a una metodología que envuelva múltiples líneas de evidencia adecuadas para el reconocimiento arqueológico de este tipo de prácticas mortuorias, son puntos claves que merecen mayor dedicación en investigaciones futuras. Esperemos que estas se desarrollen en la región y que ayuden a ampliar las muestras bioarqueológicas para análisis y comparación. Dejamos así abierta la discusión sobre la práctica —real o imaginaria- de los sacrificios humanos en Aguada, con la propuesta de reexaminar críticamente los diversos tipos de evidencia existentes (iconográfica, arqueológica, bioarqueológica, etc.), dando un énfasis especial a lo que -en particular - los huesos y sus contextos arqueológicos tienen para decir al respecto.

\section{Agradecimientos}

Ana Solari agradece a las becas CAPES-PNPD que financian actualmente sus actividades posdoctorales en la Universidad Federal de Pernambuco. Inés Gordillo realiza sus investigaciones actuales en el marco del proyecto UBACYT 20020130100108BA01 de la Universidad de Buenos Aires y agradece a todos aquellos - muchos por cierto- que han participado en las excavaciones de La Rinconada. Ambas autoras agradecen a Carlos Nazar, Guillermo de la Fuente y Lucas Gheco por la gentileza de autorizar el uso de las imágenes de la figura $1 \mathrm{C}$.

\section{Referencias citadas}

BAFFI, I. E. \& TORRES, M. F., 1995-1996 - Los restos óseos humanos del sitio Martínez 4 (Ambato, Catamarca). Publicaciones Arqueológicas, 48: 55-64; Córdoba: CIFFyH, UNC.

BASS, W. M., 1987 - Human Osteology. A Laboratory and Field Manual, 327 pp.; Columbia: Missouri Archaeological Society. Tercera edición.

BENSON, E. P. \& COOK, A. G. (eds.), 2001 - Ritual Sacrifice in Ancient Peru, 211 pp.; Austin: University of Texas Press.

BOONE, E. H. (ed.), 1984 - Ritual Human Sacrifice in Mesoamerica, viii + 247 pp.; Washington, D.C.: Dumbarton Oaks Research Library and Collection.

BOTELLA, M. C., ALEMÁN, I. \& JIMÉNEZ, S. A., 1999 - Los huesos humanos. Manipulación y alteraciones, 250 pp.; Barcelona: Bellaterra.

BOURGET, S., 1998 - Pratiques sacrificielles et funéraires au site moche de la Huaca de la Luna, côte nord du Pérou. Bulletin de I'Institut Français d'Études Andines, 27 (1): 41-74.

BROTHWELL, D. R., 1987 - Desenterrando huesos. La excavación, tratamiento y estudio de restos del esqueleto humano, 286 pp.; México: Fondo de Cultura Económica. 
BUIKSTRA, J. E. \& UBELAKER, D. H. eds., 1994 - Standards for data collection from human skeletal remains, 272 pp.; Arkansas. Archaeological Survey Research Series, n. ${ }^{\circ} 4$.

CASO, A., 1953 - El Pueblo del Sol, 125 pp.; México: Fondo de Cultura Económica.

CALLEGARI, A. \& GONALDI, M. E., 2006 - Análisis comparativo de procesos históricos durante el período de integración regional en valles de la provincia de La Rioja (Argentina). Chungará. Revista de Antropología Chilena, 38 (2): 197-210.

CAZENEUVE, J., 1971 - Sociología del rito, 284 pp.; Buenos Aires: Amorrortu editores.

CRUZ, P. J., 2004 - Archéologie de la mort dans la vallée d'Ambato : homme et milieu dans le bassin de Los Puestos (Catamarca-Argentine) durant la période d'intégration régionale (IVe-Xe siècles après J.-C.); París: Universidad de París I Panteón Sorbonne. Tesis de Doctorado.

CRUZ, P. J., 2006 - La muerte y sus manifestaciones en el valle de Ambato (Cuenca de Los Puestos, Catamarca, Argentina). In: La Cultura de la Aguada y su dispersión: 43-51; San Pedro de Atacama: Universidad Católica del Norte. IV Mesa Redonda.

DILLEHAY, T. D. (ed.), 1995 - Tombs for the Living: Andean Mortuary Practices. A Symposium at Dumbarton Oaks: 12th and 13th October, 1991, 425 pp.; Wasington D.C.: Dumbarton Oaks Research Library and Collection.

DUVERGER, C., 1979 - La fleur létale. ÉConomie du sacrifice aztèque, 249 pp.; París: Seuil.

EECKHOUT, P. \& OWENS, L. S., 2008 - Human Sacrifice at Pachacamac. Latin American Antiquity, 19 (4): 375-398.

FABRA, M., 2005 - Tecnología cerámica y cambio social en las sociedades agrícolas prehispánicas. Valle de Ambato, Catamarca. In: La Cultura de La Aguada y sus Expresiones Regionales: 1-14; La Rioja: EUDELAR. Universidad Nacional de La Rioja.

FEREMBACH, D., SCHWIDETZKY, I. \& STLOUKAL, M., 1979 - Recommandations pour déterminer l'âge et le sexe sur le squelette. Bulletin et Mémoires de la Societé d'Anthropologie de Paris, 6 (1): 7- 45.

FIGUEROA, G., DANTAS, M. \& LAGUENS, A., 2010 - Prácticas agropastoriles e innovadores en la producción de plantas y animales en los Andes del Sur. El valle de Ambato, Argentina, Primer milenio d. C. International Journal of American Archaeology, 7: 6-13.

GASTALDI, M. R., 2010 - Cultura material, construcción de identidades y transformaciones sociales en el valle de Ambato durante el primer milenio d. C.; La Plata: Universidad Nacional de La Plata. Tesis de doctorado.

GEAKE, H., 1992 - Burial practice in 7th and 8th century England. In: The Age of Sutton Hoo (M. Carver, ed.): 83-94; Woodbridge, England: The Boydell Press.

GONAldi, M. E., CAlleGARI, A., RODRíGueZ, M. G. \& SPENGler, G., 2007 Comportamiento mortuorio en el sitio La Cuestecilla (dpto. de Famatina, La Rioja). In: Actas del XVI Congreso Nacional de Arqueología Argentina, Tomo II: 53-57; Jujuy: Universidad Nacional de Jujuy.

GONZÁLEZ, A. R., 1961-1964 - La cultura de La Aguada del N.O Argentino. Revista del Instituto de Antropología, tomo II-III: 205-253; Córdoba.

GONZÁLEZ, A. R., 1983 - Nota sobre religión y culto en el noroeste argentino prehispánico. Baessler-Archiv, Neue Folge, Band XXXI: 219-282; Berlín.

GONZÁlEZ, A. R., 1998 - Cultura La Aguada; Arqueología y Diseños, xxx +336 pp.; Buenos Aires: Filmoediciones Valero. 
GONZÁLEZ, A. R. \& BALDINI, M. I., 1992 - La Aguada y el proceso cultural del NOA: Origen y relaciones con el área andina. Boletín del Museo Regional de Atacama, 4: 6-24; Copiapó, Chile.

GONZÁLEZ TORRES, Y., 1985 - El Sacrificio humano entre los mexicas, 329 pp.; México: Fondo de Cultura Económica, INAH.

GORDILLO, I., 1994 - Arquitectura y Religión en Ambato. Organización socio-espacial del ceremonialismo. Publicaciones del CIFFyH. Arqueología, 47: 55-110; Córdoba: $\mathrm{CIFFyH}, \mathrm{UNC}$.

GORDILLO, I., 2004 - Organización socioespacial y religión en Ambato: el sitio ceremonial La Rinconada, Ambato; Buenos Aires: Universidad de Buenos Aires, Facultad de Filosofía y Letras. Tesis de Doctorado.

GORDILLO, I., 2007 - Detrás de las paredes... Arquitectura y espacios domésticos en el área de La Rinconada (Ambato, Catamarca). In: Procesos Sociales Prehispánicos en los Andes Meridionales: Perspectivas desde la casa, la comunidad y el territorio (A. Nielsen, C. Rivolta, V. Seldes, M. M. Vázquez \& P. H. Mercolli, eds.): 65-98; Córdoba: Editorial Brujas.

GORDILLO, I., 2010 - La Imagen del felino en la América precolombina, 184 pp.; Buenos Aires: Academia Nacional de la Historia, Grupo Abierto Libros. Corpus Antiquitatum Americanensium VIII.

GORDILLO, I. \& SOLARI, A., 2009 - Prácticas mortuorias entre las poblaciones Aguada del valle de Ambato (Catamarca, Argentina). Revista española Antropología Americana, 39 (1): 31-51.

GRAULICH, M., 2005 - Le sacrifice humain chez les Aztèques, 415 pp.; París: Fayard.

HERRERO, R. \& ÁVILA, A., 1991 - Excavaciones en la unidad residencial SCatAmb 004 (Martínez 4) del Período de Integración Regional. Publicaciones de Arqueología, 46: 111-130; Córdoba: CIFFyH, UNC.

HUBERT, H. \& MAUSS, M., 1929 [1899] - Essai sur la nature et la fonction du sacrifice. In: Mélanges d'histoire des religions: 1-130; París: Librairie Félix Alcan.

JUEZ, S., 1991 - Unidad arqueológica Rodeo Grande, valle de Ambato: excavación en el sitio Martínez 2. Arqueología, 46: 87-110; Córdoba: CIFFyH, UNC.

LAFONE QUEVEDO, S., 1890 - Notas arqueológicas. A propósito de un objeto de arte indígena. Anales del Museo de la Plata, Sección Arqueología, 1: 3-13.

LAGUENS, A., 2004 - Arqueología de la diferenciación social en el valle de Ambato, Catamarca, Argentina (s. II-VI d. C.): el actualismo como metodología de análisis. Relaciones, 29: 137-161; Buenos Aires.

LÓPEZ LUJÁN, L., 1993 - Las ofrendas del Templo Mayor de Tenochtitlan, 432 pp.; México: INAH.

MALAFOURIS, L., 2007 - Before and beyond representation: Towards an enactive conception of the Palaeolithic image. In: Image and Imagination: a Global History of Figurative Representation (C. Renfrew \& I. Morley, eds.): 289-302; Cambridge: McDonald Institute for Archaeological Research.

MARCONETTO, M. B., 2005 - Recursos forestales y el proceso de diferenciación social en tiempos prehispánicos. Valle de Ambato, Catamarca; La Plata: Universidad Nacional de La Plata, Facultad de Ciencias Naturales y Museo. Tesis de Doctorado.

NAZAR, C., DE LA FUENTE, G. \& GHECO, L., 2013 - Avances en la caracterización de las mezclas pigmentarias del arte rupestre de la cuenca Ipizca-Icaño. Primer Taller de Arqueología de la Sierra de Ancasti; Catamarca: Universidad Nacional de Catamarca.

OESTIGAARD, T., 2000 - Sacrifices of raw, cooked and burnt humans. Norwegian Archaeological Review, 33 (1): 41-58. 
PÉREZ GOLLÁN, J. A. \& HEREDIA, O., R. 1987 - Hacia un replanteo de la cultura de La Aguada. Cuadernos, 12: 161-178; Buenos Aires: Instituto Nacional de Antropología.

PÉREZ GOLLÁN, J. A., BONNIN, M., LAGUENS, A., ASSANDRI, S., FEDERICI, L., GUDEMOS, M., HIERLING, J. \& JUEZ, S., 1996-1997 - Proyecto Arqueológico Ambato: Un Estado de la Cuestión. Shincal, 6: 115-123; Catamarca.

SCHAEFER, M., BLACK, S. \& SCHEUER, L., 2009 - Juvenile Osteology: A Laboratory and Field Manual, xii + 369 pp.; London-San Diego: Elsevier Academic Press.

SCHEUER, L. \& BLACK, S., 2004 - The juvenile skeleton, viii + 485 pp.; London-San Diego: Elsevier Academic Press.

SCHIFFER, M., 1972 - Archaeological context and sistemic context. American Antiquity, 37 (2): 156-165.

SEMPÉ, M. C., 1987 - La colección Benjamín Muñiz Barreto del Museo de La Plata. Novedades del Museo de La Plata, vol. 1, n. ${ }^{\circ}$ 11: 92-93.

SEMPÉ, M. C., 1999 - Evidencias de ceremonialismo en sitios habitacionales y funerarios en la región valliserrana catamarqueña. Contribución Arqueológica, 5 (I): 861-873; Copiapó, Chile.

SEMPÉ, M. C., 2003 - El ritualismo y los sacrificios humanos en la cultura Aguada. In: La Cultura Aguada y sus Expresiones Regionales: 53-63; La Rioja: EUDELAR, Universidad Nacional de La Rioja.

SEMPÉ, M. C., SALCEDA, S. A. \& MÉNDEZ, M. G., 2006 - Paleodemografía en el cementerio La Aguada Orilla Norte. In: La Cultura de La Aguada y su dispersión: 99-106; San Pedro de Atacama: Andros Impresores.

SOLARI, A., OLIVERA, D., GORDILLO, I., BOSCH, P., FETTER, G., LARA, V. \& NOVELO, O., 2015 - Cooked Bones? Method and Practice for Identifying Bones Treated at Low Temperature. International Journal of Osteoarchaeology, 25 (4): 426-440.

SUTTER, R. C. \& CORTEZ, R. J., 2005 - The Nature of Moche Human Sacrifice: A Bio Archaeological Perspective. Current Anthropology, 46 (4): 521-549.

TIESLER, V. \& CUCINA, A. (eds.), 2007 - New Perspectives on Human Sacrifice and Ritual Body Treatments in Ancient Maya Society, 319 pp.; Nueva York: Springer. https://www.academia.edu/1175815/Tiesler_Vera_y_Andrea_Cucina_2007_._ New_Perspectives_on_Human_Sacrifice_and_Ritual_Body_Treatments_in_Ancient_Maya_Society

TOYNE, J. M., 2015 - The body sacrificed: A bioarchaeological analysis of ritual violence in ancient Tucume, Peru. Journal of Religion and Violence, 3 (1): 137-171.

VAN GENNEP, A., 1972 [1909] - The Rites of Passage, 198 pp.; Chicago: The University of Chicago Press.

VERANO, J. W., 1995 - Where Do They Rest? The Treatment of Human Offerings and Trophies in Ancient Peru. In: Tombs for the living: Andean mortuary practices (T. D. Dillehay, ed.): 189-227; Washington, D.C.: Dumbarton Oaks Research Library and Collection.

VERANO, J. W., 2001 - The Physical Evidence of Human Sacrifice in Ancient Peru. In: Ritual Sacrifice in Ancient Peru (E. P. Benson \& A. G. Cook, eds.): 165-184; Austin: University of Texas Press.

VERANO, J. W. \& ROSSEN, J., 2011 - Human Remains. In: From foraging to farming in the Andes. New perspectives on food production and social organization (T. D. Dillehay, ed.): 163-175; Cambridge: Cambridge University Press.

UBELAKER, D. H., 1978 - Human Skeletal Remains: excavation, analysis, interpretation, 116 pp.; Chicago: Aldine Pub.Co. 
WHITE, T. D. \& FOLKENS, P. A., 2000 - Human Osteology, 563 pp.; California: Academic Press. Segunda edición.

WHITE, T. D. \& FOLKENS, P. A., 2005 - The Human Bone Manual, xx + 488 pp.; California: Elsevier Academic Press. 